\title{
Patient empowerment: Emancipatory or technological practice?
}

\author{
Stewart Piper * \\ Faculty of Health and Social Care, Anglia Ruskin University, Peterborough, UK
}

\section{ABSTRACT}

Objective:

To describe the meaning of the theme of empowerment from research on health promotion in nursing from the perspective of nurses participating in the study.

\section{Methods:}

Manual data analysis and QSR NUD*IST Vivo were used to analyse the data generated by individual and focus group interviews and the critical incident technique with 32 qualified nurses working in an acute hospital setting in the UK.

\section{Results:}

The participants identified a number of issues related to the theme of empowerment. These included the nurse as patient informer, psychological supporter and rapport builder and the concepts of informed choice/decision making, gatekeeping, coping, patient assertiveness, self-esteem and confidence.

\section{Conclusion:}

Empowerment is a complex, multi-dimensional, contested concept which can reflect a broad socio-political agenda, a radical emancipatory process or, as the findings from this qualitative study suggest, pragmatic interventions operating within the confines of a slightly modified medical model.

\section{Practice implications:}

If the reader deems the findings are transferable to their clinical milieu then the implications for practice relate to the need for careful consideration about empowerment in relation to operational definitions for practice, how terminology and related intervention is contextualised and the relationship between pragmatic empowerment and the medical paradigm.

\section{Introduction}

The aim of this small scale, situated, qualitative study was to explore the definition and the meaning nurses gave to health promotion and the associated processes and consequences, establish their degree of fit with existing theory and synthesise and translate the latter for nursing. From the findings, empowerment emerged as an important theme and this is not surprising for two reasons. Firstly, it has been advanced as the health promotion model of choice for contemporary practice [1,2], and is a key model for individual and community intervention in Piper's [3] framework. This health promotion framework creates a theoretical orientation for empowerment and can be used to contextualise and frame the findings from this study in relation to a power analysis, epistemology and individual/population modes of intervention.

Secondly, empowerment is embedded in the language of current health policy, the literature and the wider consumer culture. It is central to UK Government plans to modernise the National Health Service (NHS) [4-7] and local government [8], create a customer focused, advocacy, informed choice and expert patient movement in the UK NHS [9-11] and is thus becoming a central feature of health care [12]. Hence, this article discusses the elements of the findings that relate to empowerment in conjunction with the pertinent literature to contextualise the emergent concepts and what these represent ideologically for nursing but which may also be transferable to other health care professionals (HCPs).

Ostensibly this interest in health care empowerment represents a desire to move away from the outdated [13], traditional and paternalistic medical model to one recognising the primacy of the patient-professional relationship, patients as decision makers and a concern to 
address patient defined needs. Moreover, in Stewart's [14] review of 21 studies on the relationship between effective physician-patient communication and health outcomes, 16 demonstrated a positive correlation between these factors, history taking and discussion on the treatment with subsequent research [15] suggesting patient centred care similarly delivers better health outcomes. Patient centred care, which is mindful of and responds to the level of involvement desired by patients, is both valued by the latter and part of a healthy HCPpatient relationship [16] although may be influenced by HCP-patient ethnic [17] and socioeconomic compatibility [18].

However, as with the definition of patient centred care [16], both the literature and the findings reported herein reveal that empowerment is by no means a straightforward concept and can mean different things to different people depending upon who is using it and in what context [19]. At one level, empowerment is concerned with individual emancipation and power via raising political consciousness for change [2]. At another it fits conceptually with informed choice, partnership working, patient participation and involvement and shared decision making [3] and with the zeitgeist of social trends and marketing strategies such as girl power [20]. But the thing is, these concepts are equally contestable and when empowerment is applied to health care practice the key question to be answered is how much power is devolved by HCPs [21].

In addition, while empowerment seems to be concerned with a levelling out of power to a greater or lesser extent between the HCP and patient, in practice the nature of the relationship [22], the expertise gap and the drive for evidence based practice [23] may contradict this process. The drive for empowerment may be contradicted further by patients being comfortable with leaving decision making relating to the management of their illness to HCPs [19] although this may be integral to, and not a rejection of, patient centred care [16]. In light of this type of complexity the research methods were carefully planned to engage with the participants on a theoretical level to facilitate exploration of conceptual issues and how they relate to practice.

\section{Methods}

The research design was driven by the desire to gain a broad understanding of health promotion, to uncover potentially different examples of intervention in different settings with different participants and thus in different situations and to maximise the opportunity for creating a spectrum of analytical variables. Real professional and biographical details are outlined in brief below to help illustrate this but pseudonyms are used throughout to preserve confidentiality.

Thirty-two qualified nurses working in an acute hospital were purposively sampled from a range of both clinical and management grades and settings which, in line with UK Government priorities, included accident and emergency, cardiac care, older people, sexual health and oncology. The latter is consistent with quaternary health promotion [24] which seeks to promote health within the boundaries imposed by the final phase of disease. Participants were recruited via an existing professional relationship with the researcher and by the use of 'gatekeeper' figures in the relevant clinical settings who publicised the research and the requests for people to participate in the study.

Of those cited in this article, phase one of the data collection comprised four early interviews with cardiac rehabilitation nurses Sue (38) and Helen (late twenties), Tracey (51, emergency care manager) and Wendy (38, executive nurse). Phase two comprised five focus groups. Participants included George (42, junior staff nurse, medicine/cardiology) and sexual health nurses Frances (32), Myra (48), Anne (34), Iris (37) and Graham (60). Cherryl (late fifties) was a service manager with Adrian (late thirties), Monica and Sheila (40,senior clinical nurses in emergency care). Edith (41,lecture/practitioner), Gemma (44, senior clinical manager), Brenda (32, practice development nurse), Val (39) and Karen (27) (team leaders/junior sisters) worked in medicine for the elderly. Louise (40) was a practice development nurse, Steve (late thirties) was a lecturer in oncology and palliative care and Sarah (27) a staff nurse specialising in breast care. Phase three of the fieldwork used the critical incident technique (CIT) with Tracey, Frances, Myra, Iris, Adrian, Gemma, Brenda and Louise. 
Individual, focus group, CIT interviews and the associated CIT qualitative questionnaire used by Benner [25] in her phenomenological study when exploring 'excellence' and competencies in nursing practice were used to collect data as they suited the theoretical nature of the study. While focus group interviews generate relatively shallow data and thus only enable a superficial understanding of phenomena, they help uncover meaning through discussion and by the way participants respond to the views of others [26-28]. Equally, the CIT is advanced as a method for highlighting deficits in knowledge and conceptualisation [29].

While not dictating the order, sequence and wording of questions [30,31] an interview guide, based on the framework of quality indicators of the society of health promotion specialists [32], was used to focus the data collection and as a basis for discussion on the process and outcomes of health promoting nursing practice. Participants were asked open ended questions about the meaning they gave to health education/promotion, asked to give examples of and describe the aim(s), methods and outcomes of health promotion interventions and any theory that informed this aspect of their role.

All the data collection episodes were audiotaped, transcribed and coded with constant comparative analysis guided by Hycner's [33] phenomenological guidelines for manual data analysis. The process involved listening to the audiotaped interviews and studying the transcripts in full before reducing the data for coding to identify:

- units of general meaning

- units of relevant meaning

- redundant data

- clusters of relevant meaning and thus categories and themes

QSR NUD*IST Vivo was then used to further analyse the data and to facilitate analysis triangulation and thus refine codes, theoretical properties, categories and themes.

All data collection, analysis, coding and the generation of categories and themes was completed by the author and it is acknowledged that the absence of a second coder to validate the findings may be perceived as a limitation of the study. The author has a background in clinical nursing, health promotion and nurse education. The study adhered to the university ethics guidelines for research and was approved by the appropriate research degree committee.

\section{Results}

As might be expected in light of the various interpretations in the literature, a range of meanings were attributed to empowerment by the participants. These included the nurse as patient informer, psychological supporter and rapport builder and the concepts of informed choice/decision making, gatekeeping, coping, patient assertiveness, self-esteem and confidence.

For George and Nick empowerment was simply disseminating information:

George: empowering the patient with the information. What they do with it then is up to them...you're giving them the information and then you're giving them the responsibility, the power to actually control their lives with more information.

Nick: you have still empowered them because they have got the information then to make choices.

In contrast, empowerment was seen to represent an interpersonal, two-way process that was more holistic in going beyond pathology to the psychological needs of patients and carers and the development of supportive and trusting nurse-patient relationships: 
Sarah: you can reduce the amount [of] psychological distress that a patient may have...it's absolutely paramount that you focus on that [holism] and you look after their psychological well-being right the way through the disease process of cancer.

Myra: it's all about developing a relationship...that they feel they can trust you...

Nurses promoted understanding of disease, dispelled myths and fears and tried to put patients at ease. Some supported patients with a critical illness at a potentially cathartic time. During this period patients may re-evaluate and reflect on their life while nurses help them think about how to make lifestyle changes.

For Myra creating the right psychological ambience meant that the patient was more likely to use the service again:

Myra: if they feel that they received the information...and the support as well initially that has been useful to them, then they will take it upon themselves to come back again and seek more information and more education, and so it can be an ongoing process as they pick up where they feel they need it.

It was also acknowledged that the support role may extend beyond the nurse-patient relationship and that offered by relatives to a gatekeeper function where nurses introduced patients and carers to former patients and both highlighted and helped them access the relevant support group. This role also extended to liaising with other health, social and pastoral care professionals. Patient support groups were seen to offer peer support and a selfhelp network for patients, partners and carers where they can meet and talk about shared experiences, frustrations and anxieties but where there is also the opportunity for a positive social outlet:

Brenda: They just need to talk to people who are in the same situation and understand because however much we empathise, if you are not in the situation yourself its quite difficult I think.

Sue: It goes from being a need to being something they enjoy doing, not for the fact because they've got a....problem and they're interested in the...issues, but they've made friends and they enjoy the social life that goes along side it.

Empowered decision making and informed choice were about information, advice and support on lifestyle, disease-specific management and treatment options or alternatives. The process was used to help patients consider the potential impact of expected outcomes, consequences and risks of a particular course of action and the concomitant alternatives to enable choice. It was likened to informed consent for surgery. Hence, there was also an acknowledgement that the nurse's perspective of what constitutes the best option may not concur with that of the patient or reflect their life context, and thus the advice of the nurse might not be followed but that was up to the patient. The latter were reassured about the conflict this may create and it was felt that the nurse should respect and accept patient decisions even though they may feel uncomfortable and find it difficult to help a patient pursue a course of action that they did not condone and that may involve some risk:

Myra: you are giving them sufficient information to help them make a choice.

Anne: You have got to let them make the decisions for themselves, you can't do it for them.

Monica: giving them advice so that they can make the right choices that are best for them or their family.

Louise: I think that people need to be given information to be able to make choices about the way that they live because what we think would be beneficial to them may not be the case from their point... 
Brenda: they have made an informed choice haven't they they have to make choices and they might not be what we agree with.

Frances: To be able to make your own decisions without being influenced or bribed by someone else, for you to feel strong enough and have the knowledge to say no and I am not going to do that.

Sarah: you discuss it again and again and again until that patient is absolutely certain that the decision they make is absolutely right for them I would advocate that and say you've got to make the decision that is absolutely right for you and your lifestyle I do feel it is very empowering.

While the concept of informed choice was advanced by many participants, and readily discussed in the terms referred to above, there was some disagreement about what this actually meant in practice. For example, Steve questioned how much choice patients really did have in relation to therapeutic options and whether in reality little more than lip service was paid to informed choice. Conversely, Edith felt strongly that her area of practice positively facilitated a choice of therapeutic interventions. As can be seen above, Sarah went further in stating that an important part of her role was not only to assist patients to make an informed choice but also to advocate for them by taking up the fight on their behalf to help them get the therapeutic interventions they wanted. This may bring the nurse into conflict with other HCPs but that was just an unfortunate by-product of empowering patients and a risk worth taking. Adrian expressed a similar sentiment in relation to pushing for patients to be given analgesia when there was some unwarranted concern on the part of others that it might mask symptoms. In addition to this, Sarah helped patients resist the pressure to have the favoured interventions of other HCPs.

While associated with helping patients cope and make the most of their situation, think positively and come to terms with the best state of health that their disease and outlook would allow, empowerment included encouraging independence, patient control and autonomy within the health care context. For Helen and Frances this meant promoting patient assertiveness and a proactive demeanour in their relationship with family and friends, with HCPs and health care institutions. It was suggested that nurses should aim at a partnership type of relationship with patients and should listen carefully to their perception of their problems, particularly those with a chronic problem who have developed expertise about their disease:

Sheila: [empowerment] is...not just information and knowledge but ways, practical ways of being able to influence what happens to them.

Helen: talk through what they should or shouldn't be doing. What if they're having side-effects from medications and they need more advice, often it's a link that I think really says to them yes it's OK to go and see your GP, and we would say yes it's a good idea to talk that through...sort of sanction them going to see their GP at times I think and you're actually helping them to know when they need to get more information, when they would need to see their doctor with symptoms or they're not happy with medications...

Myra: by empowering them really to take control...it also gives them the confidence that they can do something about it to prevent it happening again...

Gemma: Patient autonomy, they keep control of their illness if you like, their routine, you are not taking anything away from them.

Sheila: to empower someone in any way in their life its not just about saying well this is the information just get on with it, its about showing them other ways about how to manage that information, to help themselves through what they want to...

Iris: What does empowerment mean to me? The facility to be able to make good life decisions. And that is what you aim to do with the patients. 
With empowerment comes improved self-esteem and confidence, an ability to exercise choice, accept responsibility for health and resist external pressure to pursue a particular course of action. This may involve the nurse in helping the patient resolve feelings of guilt and self-blame. Confidence was also related to the ability of patients to prevent future psychological and physical health problems by enacting empowerment strategies. It included the right of individuals to change situations deleterious to their health and wellbeing, about not victim blaming and helping patients to avoid feelings of rejection. There were also two indirect aspects of empowerment. Firstly, reference was made to patient held records, a small institutional gesture toward the process of empowering patients. Secondly, it involved promoting patient independence, expertise and skills retention via advocating for a group of patients to achieve some autonomy through self-medication.

It was recognised that hospital routine and patient autonomy may clash and that there may be a tension between nurse defined therapeutic need and patient choice. Medication was cited as an example of the former where there was a need for flexibility and the hospital, in not allowing self-medication, created a problem by deskilling patients. Patients managed their medication at home to good effect but then had to fit in with ward routine when in hospital.

\section{Discussion and conclusion}

\subsection{Discussion}

The theme of empowerment suggested patient centred, holistic practice responsive to patient needs involving a reduction in the 'social distance' [34] between the patient and the nurse and a move away from compliance based, nurse directed intervention and outcomes. However, the focus and nature of the relationship could also be interpreted as little more than a modest, evolutionary development of traditional roles, practices and disparities constrained by context, i.e. an acute hospital setting, the concomitant professional-patient social hierarchy, knowledge gap, power structures and the limitations imposed by the treatment options and resources available. Access to the latter was controlled by the HCPs including the nurses cited herein with control extending to the identification, prioritisation and management of care needs [35,12]. Piper [3] draws on Skelton's 1994 work to highlight how this process can be embedded within a history of lay-professional power relations and of Piper [3] who would see this as a helping (rather than an empowering) relationship which can be disabling, exploitive and actually reinforce rather than reduce the power base of HCPs.

For Jack [36] interventions, for example, like those described by the participants herein concerned with information giving or even rapport building and developing supportive and trusting relationships, are not about empowerment as there is no real devolution of power from HCPs to patients and no challenging of social inequalities or HCP-patient hierarchies. So while these aspects of practice are clearly different their focus, together with hospital policy and institutional processes operationalised by HCPs, is on the relationship between disease, risk factors and lifestyle with empowerment interventions helping patients accept and cope within a framework of medicalisation. This was reflected in Gott and O'Brien's [37] findings where empowerment equated with expert led, disease focused and primary prevention type interventions.

Information giving then, which was identified as an important part of the health promotion role by participants, is not empowering per se, or in any way an empowerment endpoint in the same way as, for example, the facilitation of informed choice, but it is an important starting point and patients cannot be empowered without information. It underpins all aspects of practice including the more developed elements of empowerment such as rapport building. And empowerment, in the context of acute hospital care, can help patients to exert some control and influence over their use of health services, treatment options and the nature of their relationship with HCPs but this is contained within, and does not go beyond, the professional and ideological context of a modified medical model. In addition, where one party can both choose to relinquish some of its power and decide how much to let go while representing powerful institutions via their professional role, it is not a true relationship of equals [21]. 
Thus, as the data suggests, intervention can be a sensitive and supportive process that genuinely seeks to respond to patient preferences in informing, enabling choice, a patient voice and a partial restructuring of the patient-professional relationship which is known to deliver positive health outcomes [14-16]. In terms of theoretical and epistemological contextualisation this fits with the empowerment model of Piper's [3] health promotion framework as HCP control is reduced and subjective patient knowledge has greater influence and more of a bottom up impact. As a form of empowerment the process is consistent with empowerment as an 'applied technology' [38], i.e. skills driven interventions concerned with effective communication [38-40], listening, patient specific information and teaching, high quality HCP-patient relationships, the facilitation of patient decision making and advocacy [38].

In modifying the HCP-patient relationship and in attenuating the control of the former, empowerment as an 'applied technology' calls for a change in practitioner and organisational thinking to accommodate such developments. For example, perceptions and policy on HCP accountability may require revision where, if informed choice is to be facilitated, autonomous patient decisions, actions and self-management outcomes make therapeutic monitoring more difficult and deliver less favourable evidence based outcomes, prognosis and achievement of clinical targets. This may be complicated further by HCPs having to make a judgement about when it is appropriate, or to what extent HCPs should try to empower when the patient's state of health or their aspirations render it inappropriate [19].

\subsection{Conclusion}

The concept of empowerment pervades UK NHS health policy but is ill defined in this context and its meaning remains contested in the wider literature. While it can reflect a broad sociopolitical agenda or be a more radical, emancipatory process, the meaning given to it by nurses participating in this small scale, situated study suggests it fits more with the concept of empowerment as a pragmatic, applied technology [38] and within the ideological context of a modified medical model. In practice this translates into providing patients with information, facilitating informed choice, moving the balance of power more toward a nurse-patient partnership and services closer to the aspirations and convenience of the latter but within a framework of pathology and boundaries outlined by the nurse. Future research should explore further the meaning of empowerment with a mix of HCPs while testing the above against new findings to help identify and delineate a range of potentially transferable HCP empowerment indicators for clinical practice.

\subsection{Practice implications}

There is no suggestion that the findings from the fieldwork and the literature are generaliseable to a wider population of HCPs or patients. However, there may be potential for transferability by the reader and thus implications for practice given the similarity of some aspects and the context and nature of acute hospital care. Or at least the findings and discussion may raise some questions for careful consideration by HCPs about:

- the ubiquitous but contestable concept of empowerment

- teaching and learning strategies for HCPs including the need for careful use of language that reflects the nature of the 'empowering' HCP-patient relationship

- elucidating the various meanings of empowerment and explicitly contextualising related terminology and practice, i.e. empowerment as a technology applied to, but delimited by, a medical context

- how empowerment can be used to extend, rather than challenge, the medical paradigm and hegemony

- the need to audit empowerment practice [3] and for self-scrutiny about interpersonal styles by HCPs.

I confirm all patient/personal identifiers have been removed or disguised so the patient/person(s) described are not identifiable and cannot be identified through the details of the story. 


\section{References}

[1] Tones K, Tilford S. Health promotion: effectiveness, efficiency and equity, $3^{\text {rd }}$ ed., London: Nelson Thornes; 2001.

[2] Tones K, Green J. Health promotion: planning and strategies. London: Sage; 2004.

[3] Piper SM. Health promotion for nurses: theory and practice. Abingdon: Routledge; 2009.

[4] Department of Health. Saving lives: our healthier nation. London: HMSO; 1999.

[5] Department of Health. The NHS plan: a plan for investment, a plan for reform. London: HMSO; 2000.

[6] Department of Health. Choosing health: making healthy choices easier. London: Department of Health; 2004.

[7] Department of Health. Patient and pubic involvement in health: the evidence of policy implementation. London: Department of Health; 2004.

[8] Seddon J. Systems thinking in the public sector. Axminster: Triarchy Press; 2008.

[9] Department of Health. The expert patient: a new approach to chronic disease management for the 21st century. London: Department of Health; 2001.

[10] Department of Health. Patient advice and liaison service. London: Department of Health; 2002.

[11] Department of Health. Long-term conditions information strategy: supporting the National Service Framework for long-term conditions. London: Department of Health; 2005.

[12] Salmon P, Hall GM. Patient empowerment or the emperor's new clothes? J Royal Soc Med 2004;97:53-6.

[13] Stevenson FA, Barry CA, Britten N, Barber N, Bradley CP. Doctor-patient communication about drugs: the evidence for shared decision making. Soc Sci Med 2000;50:829-40.

[14] Stewart MA. Effective physician-patient communication and health outcomes: a review. Can Med Assoc 1995;152:1423-35.

[15] Stewart M, Belle J, Brown P, Donner A, McWhinney I, Oates J, et al. The impact of patient-centred care on outcomes. J Fam Prac 2000;49:796-804.

[16] Stewart M. Towards a global definition of patient centred care. Brit Med J 2001;322:4445.

[17] Cooper LA, Roter DL, Johnson RL, Ford DE, Steinwachs DM, Powe NR. Patientcentred communications, ratings of care, and concordance of patient and physician race. Ann Intern Med 2003;139:907-15.

[18] Willems S, De Maesschalck S, Deveugele M, Derese A, De Maeseneer J. Socioeconomic status of the patient and doctor-patient communication: does it make a difference? Patient Educ Couns 2005;56:139-46.

[19] Lewin D, Piper SM. Patient empowerment within a coronary care unit. Intensive Crit Care Nurs 2007;23:81-90.

[20] Lovemore L, Dann KL. Empowerment in nursing: the role of philosophical and psychological factors. Nurs Philos 2002;3:234-9.

[21] Cribb A, Duncan P. Health promotion and professional ethics. Oxford: Blackwell Science; 2002.

[22] Hewitt-Taylor J. Challenging the balance of power: patient empowerment. Nurs Stand 2004;18:33-7.

[23] McQueen D, White PD, Fuller R, Sharpe MC. Discomfort of patient power. Brit Med J 2002;324:1214.

[24] Scriven A. Promotion health: perspectives, principles, practice. In: Scriven A, editor. Health promoting practice: the contribution of nurses and allied health professionals. Basingstoke: Palgrave Macmillan; 2005.

[25] Benner P. From novice to expert: excellence and power in clinical nursing practice. California: Addison-Wesley; 1984.

[26] Stewart DW, Shamdasani PN. Focus groups: theory and practice. Newbury Park: Sage; 1990.

[27] Carey MA. The group effect in focus groups: planning, implementing, and interpreting focus group research. In: Morse $\mathrm{J}$, editor. Critical issues in qualitative research methods. Thousand Oaks: Sage; 1994. p. 225-41.

[28] Kitzinger J. Introducing focus groups. Brit Med J 1995;311:299-302.

[29] Twelker PA. The critical incident technique: a manual for its planning and implementation; 2003, http://wvvw.tiu.edu/psychology/Twelker/critical_incident_technique.htm. 
[30] Patton ML. Qualitative evaluation and research methods. London: Sage; 1990.

[31] Holloway I, Wheeler S. Qualitative Research for Nurses. Oxford: Blackwell; 1996.

[32] Totten C, editor. Developing quality in health education and health promotion: a manual for all those involved in the delivery of a quality service. The Society of Health Education and Health Promotion Specialists; 1992.

[33] Hycner RH. Some guidelines for phenemenological analysis of interview data. Hum Stud 1985;8:279-303.

[34] Beattie A. Knowledge and control in health promotion: a test case for social policy and social theory. In: Gabe J, Calnan M, Bury M, editors. The sociology of the health service. London: Routledge; 1991. p. 162-202.

[35] Latter S. Health promotion in the acute setting: the case for empowering nurses. In: Kendall S, editor. Health and empowerment: research and practice. London: Arnold; 1998. p. 9-35.

[36] Jack R. Empowerment in community care. London: Chapman Hall; 1995.

[37] Gott M, O'Brien M. The role of the nurse in health promotion. Health Prom Int 1990;5:137-43.

[38] Tones K. Health promotion: the empowerment imperative. In: Scriven A, Orme J, editors. Health promotion: professional perspectives. Basingstoke: Palgrave; 2001. p. 3-18.

[39] Faulkner M. Empowerment and disempowerment: models of staff/patient interaction. NT Res 2001;6:936-50.

[40] Laverack G. Public health: power, empowerment \& professional practice. Basingstoke: Palgrave MacMillan; 2005. 